\title{
Insulin pathway related genes and risk of colorectal cancer: INSR promoter polymorphism shows a protective effect
}

\author{
Sonali Pechlivanis ${ }^{1}$, Barbara Pardini ${ }^{2,3}$, Justo Lorenzo Bermejo ${ }^{1}$, Kerstin Wagner ${ }^{1}$, \\ Alessio Naccarati ${ }^{2}$, Ludmila Vodickova ${ }^{2,4}$, Jan Novotny ${ }^{5}$, Kari Hemminki $^{1,6}$, \\ Pavel Vodicka ${ }^{2}$ and Asta Försti ${ }^{1,6}$
}

\author{
${ }^{1}$ Division of Molecular Genetic Epidemiology, German Cancer Research Center (DKFZ), Im Neuenheimer Feld 580, 69120 \\ Heidelberg, Germany \\ ${ }^{2}$ Department of Molecular Biology of Cancer, Institute of Experimental Medicine, Academy of Science of Czech Republic, Videnska \\ 1083, 14220 Prague 4, Czech Republic \\ ${ }^{3}$ Department of Biology, University of Pisa, via Derna, Pisa 56127, Italy \\ ${ }^{4}$ National Institute of Public Health, Centre of Occupational Health, Srobarova, 10042 Prague 10, Czech Republic \\ ${ }^{5}$ Department of Oncology, General Teaching Hospital, U Nemocnice 2, 12808 Prague 2, Czech Republic \\ ${ }^{6}$ Karolinska Institute, Center for Family and Community Medicine, Alfred Nobels allé 12, 14183 Huddinge, Sweden
}

(Correspondence should be addressed to A Försti; Email: a.foersti@dkfz-heidelberg.de)

\begin{abstract}
Western lifestyle leading to obesity and type 2 diabetes has been associated with increased risk of colorectal cancer $(\mathrm{CRC})$. Diet and related factors may affect the risk by modifying plasma insulin levels. Thus, the inter-individual variation in insulin signaling may play a plausible role in the development of CRC. We hypothesized that functional polymorphisms in the insulin pathway genes INS, INSR, IGFBPI, insulin receptor substrate 1 (IRS1), and IRS2 may be associated with CRC. We studied the association of five single nucleotide polymorphisms (SNPs) with the risk of CRC using a hospital-based case-control design with 712 cases and 748 controls from the Czech Republic. The INSR A-603G promoter SNP, which is located within a known Sp1-binding site, was associated with the risk of CRC, with carriers of the $G$ allele having a decreased risk (odds ratios (OR) $0.71,95 \%$ confidence interval $(\mathrm{Cl})$ 0.54-0.93). Carrying the variant allele of the IRS1 Gly972Arg SNP further decreased the risk among the INSR-603G allele carriers (OR $0.28,95 \% \mathrm{Cl} 0.11-0.70$ ). SNPs in the INS, IGFBPI, and IRS2 genes did not affect the risk of CRC. In conclusion, genetic variation in the insulin signaling pathway genes may affect the risk of CRC.
\end{abstract}

Endocrine-Related Cancer (2007) 14 733-740

\section{Introduction}

Twin studies indicate that hereditary factors contribute to $\sim 35 \%$ colorectal cancer (CRC) susceptibility, while the remaining $65 \%$ are due to random and shared environmental factors (Lichtenstein et al. 2000). High penetrance mutations in the adenomatous polyposis coli gene and the mismatch repair gene family contribute to only a small proportion of the familial component (de la Chapelle 2004). However, there are also several low-penetrance variants that contribute to CRC susceptibility (de la Chapelle 2004). Aging and lifestyle factors like diet, cigarette smoking, alcohol consumption, and lack of physical activity, influence the risk of CRC as well (Giovannucci 2001, de la Chapelle 2004). The effect of these lifestyle factors on the risk of CRC may be mediated through the insulin (INS) pathway (Giovannucci 2001, Sandhu et al. 2002), thus creating a hypothesis that genetic variation in the genes along the pathway may affect the risk of CRC.

There are several pieces of evidence indicating that insulin is associated with the risk of CRC (Giovannucci 2001, Sandhu et al. 2002). In rats, insulin enhances the growth of aberrant crypt foci, CRC precursor lesions, and increases the number and the size of the tumors (Giovannucci 2001). Several studies have also found 
a link between insulin, type 2 diabetes, obesity and body size and the risk of CRC (Schoen et al. 1999, Giovannucci 2001, Calle \& Kaaks 2004, Biddinger \& Kahn 2006). There is also an evidence on the association between the elevated levels of insulin and an increased risk of CRC in humans (Schoen et al. 1999, Kaaks et al. 2000).

Insulin may regulate cell growth and apoptosis by binding to its receptor (INSR) or to the structurally related insulin-like growth factor-I receptor (IGFIR; LeRoith \& Roberts 2003, Biddinger \& Kahn 2006). However, it is a rather weak mitogen and may promote colorectal carcinogenesis indirectly by regulating production of the more potent mitogen, IGFI (Giovannucci 2001, Sandhu et al. 2002). Growth hormone is the main regulator of IGFI. By up-regulating the production of growth hormone receptor, insulin increases the production of IGFI. Insulin also decreases the levels of two IGF-binding proteins (IGFBPI and IGFBP2), thus affecting the bioavailability of IGFI. The insulin receptor substrates (IRSs) and Src homology 2 domain-containing transforming protein 1 (SHC1) are the key mediators of the INS and IGFI pathways (LeRoith \& Roberts 2003, Biddinger \& Kahn 2006). Both IRS1 and SHC1 can bind to growth factor receptor bound protein 2 (GRB2) to activate the Ras/ MAP kinase pathway that regulates cell proliferation and differentiation. The IRS proteins 1 and 2 can additionally bind to the p85 subunit of phosphatidylinositol (PI)-3 kinase and activate the serine kinase $\mathrm{PKB} / \mathrm{Akt}$ pathway that regulates apoptosis, glucose metabolism, and lipid biosynthesis.

So far, prostate cancer is the most intensively studied cancer with regard to the effect of polymorphisms in the INS, IRSI, IRS2, and IGFBPI genes on cancer susceptibility (Ho et al. 2003, Claeys et al. 2005, Li et al. 2005, Neuhausen et al. 2005, Stephens et al. 2005, Cheng et al. 2006). Only one study has focused on IRS1 and IRS2 polymorphisms and the risk of CRC (Slattery et al. 2004). Additionally, a study investigating the relationship between genetic variation in the INS, INSR, IRS1, and IRS 2 genes and advanced colorectal adenoma, a cancer precursor, has been published (Gunter et al. 2007).

In the INS gene, a variable number of tandem repeats (VNTR) locus that lies next to the transcription start site, is believed to have a direct effect on insulin regulation (Bennett \& Todd 1996). Tight linkage disequilibrium (LD) has been reported between several single nucleotide polymorphisms (SNPs) and the VNTR (Bennett \& Todd 1996). Several groups have studied the relationship between prostate cancer and one of the linked SNPs, +1127INSPstI, with inconsistent results (Ho et al. 2003, Claeys et al. 2005, Li et al. 2005, Neuhausen et al. 2005).

The $5^{\prime}$-flanking region of the INSR gene plays an important role in proper expression of the gene (Foti et al. 2003). There are many regulatory elements present in the promoter region, including four clusters of GC boxes that have been reported to be putative binding sites for the transcription factor Sp1 (Araki et al. 1991, Haruta et al. 1995, Foti et al. 2003). Polymorphisms that are located in this region may affect the gene expression with subsequent impairment of insulin signaling and action.

High LD has been reported across the entire IGFBPI gene (Stephens et al. 2005, Cheng et al. 2006). The Ile253Met SNP is the only validated non-synonymous SNP and has been associated with diabetic nephropathy (Stephens et al. 2005).

In the IRSI and IRS 2 genes, polymorphisms that are located close to the tyrosine phosphorylation sites may cause a change in the tertiary structure of these proteins and therefore may show an effect on p85 and GRB2 binding, resulting in impaired signaling (Wagner et al. 2004).

Here, we investigated the effect of SNPs in several insulin pathway-related genes on the risk of CRC. We selected SNPs in the INS, IGFBPI, INSR, IRSI, and $I R S 2$ genes based on their suggested effect on the gene expression or the protein function or because they were in LD with a putatively functional polymorphism. We investigated their association with the risk of CRC in a Czech hospital-based case-control population with 712 cases and 748 controls. We additionally evaluated the effect of gene-gene interactions on the risk of CRC.

\section{Materials and methods}

\section{Subjects}

The present hospital-based case-control study is based on incident cases, the recruitment of which started in September 2004 and ended in February 2006. Blood samples and anamnestic data were provided by six oncological and five large gastroenterological departments all over the Czech Republic. The study cases consist of patients with positive colonoscopic results for malignancy, histologically confirmed as colon or rectal carcinomas. Controls were defined as subjects undergoing colonoscopy for various gastrointestinal complaints and sampled at the same time as cases. Their colonoscopic results were negative for malignancy or idiopathic bowel diseases.

Study subjects provided the information on their lifestyle habits (smoking, drinking, diet, etc.), body 
mass index (BMI), diabetes, tentative occupational exposure to xenobiotics, and family/personal history of cancer, with the use of structured questionnaires. Table 1 shows the selected characteristics of the study population at the time of diagnosis of the cases and at the time of sample drawing of the controls respectively. The information about diabetes was selfreported.

Blood samples were collected from 712 CRC patients (mean age 62, range 27-90) and 748 regionally matched controls (mean age 53.5, range 29-91). DNA was isolated from coded blood samples and stored at $-80^{\circ} \mathrm{C}$.

All participants signed an informed written consent and the design of the study was approved by the Ethical Committee of the Institute of Experimental Medicine, Prague, Czech Republic.

\section{SNP selection}

We sequenced 23 samples in order to screen the entire INS and IGFBPI gene regions, the promoter $(-2221$ to $-1 \mathrm{bp}$ ) and the published SNPs (http://www.ncbi.nlm. nih.gov/, http://snpper.chip.org/) in the coding region of the INSR gene.

We confirmed high LD in the INS gene and selected the +1127INSPstI SNP (rs3842752) for further analysis because it has been previously used as a surrogate for the functional VNTR polymorphism in studies of diseases related to insulin resistance, including cancer (Ho et al. 2003, Claeys et al. 2005, Li et al. 2005, Neuhausen et al. 2005). In the IGFBPI gene, the only non-synonymous SNP Ile253Met (rs4619) was in 100\% LD with all the other SNPs along the entire IGFBPI gene region as previously shown by Cheng et al. (2006) and therefore, we selected it for further analysis. In the INSR gene, four promoter and eight coding region SNPs were confirmed. The A-603G SNP (rs1864010) lies within a Sp1-binding site and was therefore selected for our further study (Foti et al. 2003). Since all the INSRcoding region SNPs caused synonymous exchanges and the two SNPs in the tyrosine kinase domain had a low minor allele frequency (MAF), $\leq 5 \%$, we did not analyze them further. The IRS1 Gly972Arg (rs1801278) and the IRS2 Gly1057Asp (rs18050907) SNPs were selected for further analysis because of their putative effect on p85 and GRB2 binding (Wagner et al. 2004).

\section{DNA sequencing}

We used DNA sequencing for the initial SNP screening, for the analyses of the INSR A-603G and IRS2 Gly1057Asp SNPs. Additionally, about $10 \%$ of the genotyping results were also confirmed. PCR amplification was performed with $5 \mathrm{ng}$ genomic DNA in a $10 \mu \mathrm{l}$ reaction volume using $1 \times \mathrm{PCR}$ buffer, $1.5 \mathrm{mM} \mathrm{MgCl}_{2}, 0.11 \mu \mathrm{M}$ dNTP mixture, $0.3 \mathrm{U}$ Platinum Tag DNA polymerase (Invitrogen) and $0.15 \mu \mathrm{M}$ each primer (Invitrogen). The primer sequences and corresponding PCR conditions used for detecting the SNPs in each gene can be obtained from the corresponding author. For the INSR promoter A-603G and the IRS2 Gly1057Asp SNPs 5\% DMSO was added to the reaction mixture. The PCR was carried out in a GeneAmp 9700 PCR system (Applied Biosystems, Foster City, CA, USA) in the following conditions: 2 min denaturation at $94{ }^{\circ} \mathrm{C}$ followed by three cycles of $94^{\circ} \mathrm{C}$ for $1 \mathrm{~min}$, the optimum annealing temperature for the respective fragment (available on request) for $1 \mathrm{~min}, 72{ }^{\circ} \mathrm{C}$ for $1 \mathrm{~min}, 32$ cycles of $94{ }^{\circ} \mathrm{C}$ for $30 \mathrm{~s}$, the optimum annealing temperature minus $1{ }^{\circ} \mathrm{C}$ for $30 \mathrm{~s}, 72{ }^{\circ} \mathrm{C}$ for $30 \mathrm{~s}$, and a final extension at $72{ }^{\circ} \mathrm{C}$ for 6 min.

The PCR product was cleaned up using $0.75 \mu \mathrm{l}$ ExoSapIT (USB Amersham) for $40 \mathrm{~min}$ at $37^{\circ} \mathrm{C}$ followed by $15 \mathrm{~min}$ at $85^{\circ} \mathrm{C}$. The sequencing reaction was carried out using the Big Dye Terminator Cycle Sequencing Ready Reaction Kit v.3

Table 1 Selected characteristics of the study population

\begin{tabular}{|c|c|c|}
\hline & Cases & Controls \\
\hline Total study population $(n)$ & 712 & 748 \\
\hline Males $(n(\%))$ & $404(56.7 \%)$ & $434(58 \%)$ \\
\hline Females $(n(\%))$ & $308(43.2 \%)$ & $314(41.9 \%)$ \\
\hline Median age (years; range) ${ }^{a}$ & $62(29-90)$ & $54(29-91)$ \\
\hline Median BMI $\left(\mathrm{kg} / \mathrm{m}^{2} ; \text { th-95th percentiles }\right)^{\mathrm{b}}$ & $26.4(20.6-34.3)$ & $26.8(21.1-34.6)$ \\
\hline Self-reported diabetes $(n(\%))^{\mathrm{b}}$ & $70(16.4 \%)$ & $38(11.1 \%)$ \\
\hline Personal history of other cancers $(n(\%))^{\mathrm{b}}$ & $40(9.5 \%)$ & $34(9.9 \%)$ \\
\hline
\end{tabular}

BMI, body mass index.

${ }^{a}$ Age data were missing from $27(3.8 \%)$ cases and $1(0.1 \%)$ control.

${ }^{\mathrm{b}}$ The data were available for 420 cases and 343 controls; data were missing from 292 (41\%) cases and 405 (54.1\%) controls. 
(Applied Biosystems). The sequencing reaction was performed using forward and reverse primers separately with the following PCR conditions: $96^{\circ} \mathrm{C}$ for $1 \mathrm{~min}, 27$ cycles of $96{ }^{\circ} \mathrm{C}$ for $16 \mathrm{~s}, 54{ }^{\circ} \mathrm{C}$ for $5 \mathrm{~s}$, and $60{ }^{\circ} \mathrm{C}$ for $4 \mathrm{~min}$. The sequencing products were precipitated with isopropanol, resuspended in $25 \mu \mathrm{l}$ water, and loaded onto an ABI PRISM 3130XL Genetic analyzer (Applied Biosystems). The original data were analyzed using Sequencing Analysis 5.2 software (Applied Biosystems) for base calling. The obtained sequences were aligned using DNAStar Lasergene 5.0 software (DNAStar Inc., Madison, WI, USA).

\section{Genotyping using Taq-Man assay}

The polymorphisms +1127INSPstI in the INS gene, Ile253Met in the IGFBPI gene, and Gly972Arg in the IRS1 gene were investigated using the allelic discrimination method. TaqMan primers and probes were ordered as Assay-on-Demand (Assay Id: C__1223316_10, C_1842782_10 and C_2384392_20 for the INS, IGFBPI, and IRSI genes respectively) from Applied Biosystems. The reaction was performed in $5 \mu \mathrm{l}$ using $225 \mathrm{nM}$ each primer, $50 \mathrm{nM}$ each probe, and $2.5 \mu \mathrm{l}$ TaqMan Universal $2 \times$ PCR Master Mix (Applied Biosystems) per reaction. PCR was performed at $50{ }^{\circ} \mathrm{C}$ for $2 \mathrm{~min}, 95^{\circ} \mathrm{C}$ for $10 \mathrm{~min}$ followed by $40-55$ cycles at $92{ }^{\circ} \mathrm{C}$ for $15 \mathrm{~s}$, and $60{ }^{\circ} \mathrm{C}$ for $1 \mathrm{~min}$. PCR was performed in a GeneAmp PCR System 9700 thermocycler and the number of cycles was dependent on the genotype clustering. The samples were read and analyzed on the ABI Prism 7900HT sequence detection system using SDS 1.2 software (Applied Biosystems, Foster City, CA, USA).

\section{Statistical analysis}

The observed genotype frequencies in controls were tested for Hardy-Weinberg equilibrium (HWE). The best model to represent the relationship between genotype and the risk of CRC was selected based on likelihood ratio tests (LRTs). Odds ratios (ORs) with 95\% confidence intervals ( $95 \%$ CIs) were estimated by logistic regression. Statistical significance for a different genotype distribution in cases versus controls was determined by global $\chi^{2}$ tests. With the present sample size, we had a power of $90 \%$ to detect an OR of 0.5 for a dominant effect of a polymorphism with $\mathrm{MAF}=5 \%$. To identify possible higher-order genegene interactions among the insulin pathway genes, the multifactor-dimensionality reduction method was applied (Ritchie et al. 2001).

\section{Results}

\section{A-603G polymorphism in INSR gene shows protective effect}

In the control population, the genotype distributions for all the five studied SNPs were according to HWE. The MAF and the genotype distribution for the INS + 1127INSPstI, IGFBPI Ile253Met, IRS1 Gly972Arg, and IRS2 Gly1057Asp were concordant with the NCBI database (http://www.ncbi.nlm.nih.gov/) and the previously published studies for Caucasians (Ho et al. 2003, Slattery et al. 2004, Li et al. 2005, Neuhausen et al. 2005, Wagner et al. 2007). No study about the INSR SNP has been published. Table 2 shows the genotype distributions of the SNPs studied in the INS, INSR, IGFBPI, IRS1, and IRS2 genes in our study population and their effect on the risk of CRC. The only significant association was found between the INSR (A-603G) genotypes and the risk of CRC (global $\chi^{2}=6.15, P=0.046$ ). For this locus, the observed genotype distributions were represented better by a dominant model than by a three-genotype model $\left(\chi^{2} \mathrm{LRT}=0.092, P=0.762\right)$. Under dominance, the estimated OR for GG/AG versus AA genotype was $0.71(95 \% \mathrm{CI}=0.54-0.93)$.

\section{Gene-gene interaction}

We investigated the mutual effect of the insulin signaling-related genes because insulin regulates the bioavailability of IGFBPI as well as it binds to its receptor to start the downstream signaling pathway through IRS1 and IRS2. Thus, the combined effect of the genotypes in these genes may be a more important risk factor for CRC than the individual genotypes. In order to investigate the possible gene-gene interactions, INSR genotypes based on the dominant model were further stratified. The stratification of INSR genotypes according to the two IRS1 genotypes (AA/GA and GG) was adequate from a statistical point of view $\left(\chi^{2} \mathrm{LRT}=7.649, P=0.022\right)$ and it constituted the best model, thus indicating a significant interaction between INSR and IRS1 genotypes on the risk of CRC. Under this model, the global $\chi^{2}$ for the genotype effect showed a significance effect $\left(\chi^{2}=9.88\right.$ $(P=0.02))$ and the estimated OR for carriers of the INSR GG/AG and the IRS1 AA/GA genotypes was 0.28 (95\% CI $=0.11-0.70)$ (Table 3). We used the multifactor-dimensionality reduction method in order to identify other gene-gene interactions between the insulin pathway genes, but no associations were detected.

Information on BMI and treatment for diabetes was available for $59.0 \%$ of the cases and $45.9 \%$ of 
Table 2 Genotype distributions of the polymorphisms in the INS, INSR, insulin-like growth factor-binding protein I (IGFBPI), insulin receptor substrate 1 (IRS1), and IRS2 genes among the colorectal cancer (CRC) cases and controls

\begin{tabular}{|c|c|c|c|c|c|c|c|}
\hline Genes & dbSNP & Genotype & Cases (\%) & $\begin{array}{c}\text { Controls } \\
(\%)\end{array}$ & Global $\chi^{2}$ & $\begin{array}{c}\text { Global } P \\
\text { value }\end{array}$ & OR $(95 \% \mathrm{Cl})^{\mathrm{a}}$ \\
\hline \multirow{3}{*}{$\begin{array}{l}\text { INS } \\
\qquad(+1127 \text { INSPstl })\end{array}$} & rs3842752 & $\mathrm{CC}$ & $403(60.4)$ & $440(61.4)$ & 1.95 & 0.378 & 1 \\
\hline & & CT & $237(35.7)$ & $241(33.6)$ & & & $1.09(0.86-1.38)$ \\
\hline & & TT & $24(3.6)$ & $36(5.0)$ & & & $0.74(0.42-1.29)$ \\
\hline \multirow[t]{4}{*}{$\operatorname{INSR}(\mathrm{A}-603 \mathrm{G})$} & rs1864010 & AA & $504(80.6)$ & $525(74.3)$ & 6.15 & 0.046 & 1 \\
\hline & & $A G$ & $108(17.3)$ & $162(22.9)$ & & & $0.70(0.53-0.93)$ \\
\hline & & $\mathrm{GG}$ & $13(2.1)$ & $20(2.8)$ & & & $0.78(0.37-1.62)$ \\
\hline & & $A G+G^{b}$ & $121(19.4)^{b}$ & $182(25.7)^{\mathrm{b}}$ & $6.09^{b}$ & $0.014^{\mathrm{b}}$ & $0.71(0.54-0.93)^{b}$ \\
\hline \multirow[t]{3}{*}{ IGFBPI (Ile253Met) } & rs4619 & AA & $305(47.0)$ & $314(44.5)$ & 1.07 & 0.585 & 1 \\
\hline & & $A G$ & $269(41.5)$ & $310(44.0)$ & & & $0.90(0.71-1.15)$ \\
\hline & & $\mathrm{GG}$ & $75(11.6)$ & $81(11.5)$ & & & $1.06(0.74-1.54)$ \\
\hline \multirow[t]{3}{*}{ IRS1 (Gly972Arg) } & rs1801278 & $G G$ & $590(88.7)$ & $627(86.4)$ & 1.13 & 0.568 & 1 \\
\hline & & $\mathrm{GA}$ & $74(11.1)$ & $96(13.2)$ & & & $0.85(0.61-1.19)$ \\
\hline & & AA & $1(0.2)$ & $3(0.4)$ & & & $0.56(0.06-5.44)$ \\
\hline \multirow[t]{3}{*}{ IRS2 (Gly1057Asp) } & rs1805097 & $\mathrm{GG}$ & $211(37.1)$ & $268(39.2)$ & 1.60 & 0.451 & 1 \\
\hline & & $\mathrm{GA}$ & $277(48.7)$ & $309(45.2)$ & & & $1.15(0.89-1.48)$ \\
\hline & & AA & $81(14.2)$ & $106(15.5)$ & & & $0.97(0.68-1.38)$ \\
\hline
\end{tabular}

Odds ratios (ORs) and 95\% confidence interval $(\mathrm{Cl})$ limits were calculated.

${ }^{a}$ Adjusted for age and sex.

${ }^{\mathrm{b}}$ Represents the dominant genotype model. The number of cases and controls varies between SNPs because of a few missing genotype data.

the controls. The BMI or the proportion of cases treated for diabetes did not depend on the INSR or the IRS2 genotypes (data not shown). Only 70 cases $(16.7 \%)$ and 38 controls (11.1\%) were reported to have diabetes. In this small subgroup of subjects, the association between development of CRC and diabetes treatment was not significant $(P=0.36)$.

\section{Discussion}

Studies linking insulin resistance, obesity, and CRC (Calle \& Kaaks 2004, Biddinger \& Kahn 2006) suggest that the insulin pathway may play an important role in the etiology of CRC (Giovannucci 2001). In order to investigate the influence of genetic variation in the insulin pathway related genes on the risk of CRC, we

Table 3 Joint effect of the polymorphisms in the INSR and insulin receptor substrate 1 (IRS1) genes in the Czech colorectal cancer (CRC) cases and controls

\begin{tabular}{llccl}
\hline $\begin{array}{l}\text { Genotype } \\
\text { INSR }\end{array}$ & IRS1 & Cases & Controls & OR $(95 \% \mathrm{Cl})^{\mathrm{a}}$ \\
\hline $\mathrm{AA}$ & $\mathrm{GG}$ & 432 & 699 & 1.00 \\
$\mathrm{AA}$ & $\mathrm{AA} / \mathrm{GA}$ & 65 & 71 & $1.00(0.69-1.45)$ \\
$\mathrm{GG} / \mathrm{AG}$ & $\mathrm{GG}$ & 113 & 155 & $0.78(0.58-1.04)$ \\
GG/AG & $\mathrm{AA} / \mathrm{GA}$ & 6 & 24 & $0.28(0.11-0.70)$ \\
\hline
\end{tabular}

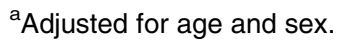

genotyped SNPs in the INS, INSR, IGFBPI, IRSI, and $I R S 2$ genes in a cohort of cases and controls from the Czech Republic.

This is the first study to evaluate the effect of variants in several genes along the INS pathway on the risk of CRC. Previously, INS, INSR, IRS1, and IRS2 SNPs have been studied with regard to advanced colorectal adenoma, a cancer precursor (Gunter et al. 2007) and only IRS1 and IRS2 SNPs with regard to the risk of CRC (Slattery et al. 2004). In our study, the variant allele carriers of the INSR gene were at a significantly decreased risk of CRC. Further stratification of the INSR genotypes showed a gene-gene interaction between the INSR and the IRSI genes. Carriers with the variant alleles of the two genes had even lower risk of CRC than the carriers of the protective INSR allele. However, although the number of carriers of the individual genotypes among controls was quite high $(25.7 \%$ for INSR and $13.6 \%$ for IRS1 respectively), only 6 cases and 24 controls carried the variant alleles of the two genes. The studied SNPs in the INS, IGFBPI, and IRS2 genes were not statistically significantly associated with the risk of CRC.

In the INSR gene, the region $1800 \mathrm{bp}$ upstream of the translation start site contains many regulatory elements which have been reported to be required for proper expression of INSR and appropriate insulin signaling 
and action (Araki et al. 1991, Foti et al. 2003). The removal or mutational inactivation of the four Sp1 elements present between -618 and -593 bp has been shown to reduce promoter activity of the gene by about $90 \%$ (Yoshizato et al. 2001, Foti et al. 2003). In the present study, we investigated the A-603G polymorphism which lies within the consensus sequence for Sp1 binding and has been shown to affect Sp1 binding (Kadonaga et al. 1986). However, a later study has not observed any effect of this SNP on the promoter activity (Haruta et al. 1995). Interestingly, in our study the $\mathrm{G}$ allele carrier status was associated with a significantly decreased risk for CRC. In consistence with our results, the A allele has been suggested to be a risk factor for insulin resistance (Kadowaki et al. 1990). Recently, Gunter et al. (2007) used haplotypetagging SNP approach to comprehensively investigate the association of genetic variation in the INSR gene with the risk of advanced colorectal adenoma. Although the studied SNPs did not seem to have any effect on the risk of adenoma, the authors found evidence of the effect modification by BMI on the association of INSR gene variants and the risk of colorectal adenoma. However, they could not find any individual SNP that would have explained the significance of the interaction. There are at least two possible explanations to the different results obtained by Gunter $e t$ al. and by us. The study by Gunter et al. did not include any SNPs in the promoter, where the A-603G SNP studied by us is located, and no data of LD between the SNPs in the promoter and the gene region are available. Another difference between these two studies is that the cases in our study were diagnosed with CRC, the cases in the study by Gunter et al. with advanced colorectal adenoma, a cancer precursor.

The IRS1 Gly972Arg polymorphism lies between two tyrosine residues, which upon phosphorylation are involved in a further interaction with the downstream signaling molecules (Wagner et al. 2004). The Arg variant has been shown to have decreased binding to the p85 regulatory subunit of PI-3 kinase, resulting in impaired insulin-stimulated signaling (Almind et al. 1996). The Gly972Arg SNP has been intensively studied for type 1 and 2 diabetes, polycystic ovary syndrome, obesity, and metabolic disorders with inconsistent results (Wagner et al. 2007). The Arg allele has been associated with an increased risk of CRC but not with breast cancer (Slattery et al. 2004, Wagner et al. 2004). In one study, the risk of prostate cancer has been shown to be increased among Arg allele carriers (Neuhausen et al. 2005), while another study found no association ( $\mathrm{Li}$ et al. 2005). In our study, the Gly972Arg SNP was not statistically significantly associated with the risk of CRC. However, the risk of the carriers of the protective INSR allele was even more decreased in individuals carrying the IRS1 Arg allele. This effect can be explained by the assumed impaired insulin signaling due to the variant alleles of these two genes (Kadowaki et al. 1990, Almind et al. 1996).

The IRS2 Gly1057Asp polymorphism also lies close to two putative phosphorylation tyrosine sites; however, no effect of its binding ability to the p85 subunit of PI-3 kinase has been observed (Wagner et al. 2004). Similar to IRS1, several studies with inconsistent effects of the IRS2 SNP have been observed in insulin resistance-related diseases (Wagner et al. 2007). No association has been detected in studies of breast and prostate cancer (Wagner et al. 2004, Neuhausen et al. 2005). In CRC, heterozygotes, but not the homozygotes, for the Asp allele, have been shown to be at reduced risk (Slattery et al. 2004). In our study, the IRS2 Gly1057Asp showed no association with the risk of CRC.

The +1127 INSPstI is located in the $3^{\prime}$-untranslated region (UTR) of the INS gene. The $3^{\prime}$-UTR plays a prominent role in mRNA stability and may thus regulate insulin production (Ho et al. 2003). It is also in LD with a VNTR locus, which has consistently shown linkage with diabetes (Bennett \& Todd 1996). Our data did not show a significant association between the SNP and the risk of CRC. Earlier, Ho et al. (2003) and Claeys et al. (2005) have suggested an association between the +1127 INSPst1 CC genotype and an increased risk of prostate cancer. However, two other studies have not found any effect of the INS SNP on the risk of prostate cancer (Li et al. 2005, Neuhausen et al. 2005).

In the recent study by Gunter et al. (2007) the effect of several SNPs in the INS, IRS1, and IRS2 genes on the risk of advanced colorectal adenoma was investigated. They selected the SNPs in each gene based mainly on their putative effect on hyperinsulinemia and insulin resistance, but they did not observe any association with adenoma. The SNPs which we studied were not included in their study in spite of their functional effects and reported linkage with different insulinrelated diseases as discussed above.

High levels of IGFBPI have been shown to significantly decrease the risk of CRC (Kaaks et al. 2000). In a study by Stephens et al. (2005) two tightly linked SNPs were associated with a reduced prevalence of diabetic nephropathy with the Ile253Met determining the strongest protection. This SNP would most likely affect some aspects of post-translational function of the protein as it is located close to the RGD motif in 
the $\mathrm{C}$ terminus and may affect the interaction with IGFI (Stephens et al. 2005). In our study, we did not observe any association of the Ile253Met polymorphism with the risk of CRC. This result is in concordance with a recent study by Cheng et al. (2006) in which they conducted a haplotype-based study and found no association with the risk of prostate and breast cancer.

Tight LD has been observed in the regions of the INS and the IGFBPI genes. In such a region, assaying for one marker would generally provide genotype information of all the others (Bennett \& Todd 1996, Stephens et al. 2005, Cheng et al. 2006). To observe a dominant effect, our study had a $90 \%$ power to detect an OR of 1.4. However, the power to detect a recessive effect was much lower $(<60 \%)$. Thus, we can only exclude a major effect of the INS and IGFBPI SNPs on the risk of CRC.

The limitations of our study include the difference in the age between the cases and the controls. However, no age- or gender-specific differences in the genotype distributions were observed. Another limitation was the limited availability of the data about BMI and diabetes, $59.0 \%$ among the cases and only $45.9 \%$ among the controls. Additionally, the BMI data of the cases were retrieved at the time of diagnosis and the data of diabetes were self-reported, restricting the usefulness of the information.

In conclusion, our results suggest a reduced risk of CRC for carriers of the INSR-603G allele. The protective effect was even stronger among carriers of both the INSR-603G and the IRS1 972Arg alleles. These results need to be confirmed in other independent sample sets. Because of a relationship between insulin-related diseases and CRC, SNPs in the insulin pathway genes may have a more prominent effect on the risk of CRC in diabetic and obese individuals, which warrants further studies.

\section{Acknowledgements}

This study was supported by a grant from EU (LSHCCT-2004-503465). B Pardini, A Naccarati, L Vodickova, $\mathrm{J}$ Novotny, and $\mathrm{P}$ Vodicka were recipients of the following grants: GACR 310/05/2626, GACR $310 / 07 / 1430$, and IGA MZ NR8563-5/2005. The authors declare that there is no conflict of interest that would prejudice the impartiality of this scientific work.

\section{References}

Almind K, Inoue G, Pedersen O \& Kahn CR 1996 A common amino acid polymorphism in insulin receptor substrate-1 causes impaired insulin signaling. Evidence from transfection studies. Journal of Clinical Investigation 97 2569-2575.

Araki E, Murakami T, Shirotani T, Kanai F, Shinohara Y, Shimada F, Mori M, Shichiri M \& Ebina Y 1991 A cluster of four Sp1 binding sites required for efficient expression of the human insulin receptor gene. Journal of Biological Chemistry 266 3944-3948.

Bennett ST \& Todd JA 1996 Human type 1 diabetes and the insulin gene: principles of mapping polygenes. Annual Review of Genetics 30 343-370.

Biddinger SB \& Kahn CR 2006 From mice to men: insights into the insulin resistance syndromes. Annual Review of Physiology 68 123-158.

Calle EE \& Kaaks R 2004 Overweight, obesity and cancer: epidemiological evidence and proposed mechanisms. Nature Reviews. Cancer 4 579-591.

de la Chapelle A 2004 Genetic predisposition to colorectal cancer. Nature Reviews. Cancer 4 769-780.

Cheng I, Penney KL, Stram DO, Le Marchand L, Giorgi E, Haiman CA, Kolonel LN, Pike M, Hirschhorn J, Henderson BE et al. 2006 Haplotype-based association studies of IGFBPI and IGFBP3 with prostate and breast cancer risk: the multiethnic cohort. Cancer Epidemiology, Biomarkers and Prevention 15 1993-1997.

Claeys GB, Sarma AV, Dunn RL, Zuhlke KA, BeebeDimmer J, Montie JE, Wojno KJ, Schottenfeld D \& Cooney KA 2005 INSPstI polymorphism and prostate cancer in African-American men. Prostate 65 83-87.

Foti D, Iuliano R, Chiefari E \& Brunetti A 2003 A nucleoprotein complex containing Sp1, C/EBP beta, and HMGI-Y controls human insulin receptor gene transcription. Molecular and Cellular Biology 23 2720-2732.

Giovannucci E 2001 Insulin, insulin-like growth factors and colon cancer: a review of the evidence. Journal of Nutrition 131 3109S-3120S.

Gunter MJ, Hayes RB, Chatterjee N, Yeager M, Welch R, Schoen RE, Yakochi L, Schatzkin A \& Peters U 2007 Insulin resistance-related genes and advanced left-sided colorectal adenoma. Cancer Epidemiology, Biomarkers and Prevention 16 703-708.

Haruta T, Imamura T, Iwanishi M, Egawa K, Goji K \& Kobayashi M 1995 Amplification and analysis of promoter region of insulin receptor gene in a patient with leprechaunism associated with severe insulin resistance. Metabolism 44 430-437.

Ho GY, Melman A, Liu SM, Li M, Yu H, Negassa A, Burk RD, Hsing AW, Ghavamian R \& Chua SC Jr 2003 Polymorphism of the insulin gene is associated with increased prostate cancer risk. British Journal of Cancer 88 263-269.

Kaaks R, Toniolo P, Akhmedkhanov A, Lukanova A, Biessy C, Dechaud H, Rinaldi S, Zeleniuch-Jacquotte A, Shore RE \& Riboli E 2000 Serum C-peptide, insulin-like growth 
factor (IGF)-I, IGF-binding proteins, and colorectal cancer risk in women. Journal of National Cancer Institute 92 1592-1600.

Kadonaga JT, Jones KA \& Tjian R 1986 Promoter-specific activation of RNA polymerase II transcription by $\mathrm{Sp} 1$. Trends in Biochemical Sciences 11 20-23.

Kadowaki T, Kadowaki H, Rechler MM, Serrano-Rios M, Roth J, Gorden P \& Taylor SI 1990 Five mutant alleles of the insulin receptor gene in patients with genetic forms of insulin resistance. Journal of Clinical Investigation $\mathbf{8 6}$ 254-264.

LeRoith D \& Roberts CT Jr 2003 The insulin-like growth factor system and cancer. Cancer Letters 195 127-137.

Li L, Cicek MS, Casey G \& Witte JS 2005 No association between genetic polymorphisms in insulin and insulin receptor substrate- 1 and prostate cancer. Cancer Epidemiology, Biomarkers and Prevention 14 2462-2463.

Lichtenstein P, Holm NV, Verkasalo PK, Iliadou A, Kaprio J, Koskenvuo M, Pukkala E, Skytthe A \& Hemminki K 2000 Environmental and heritable factors in the causation of cancer - analyses of cohorts of twins from Sweden, Denmark, and Finland. New England Journal of Medicine 343 78-85.

Neuhausen SL, Slattery ML, Garner CP, Ding YC, Hoffman M \& Brothman AR 2005 Prostate cancer risk and IRS1, IRS2, IGFI, and INS polymorphisms: strong association of IRS1 G972R variant and cancer risk. Prostate 64 168-174.

Ritchie MD, Hahn LW, Roodi N, Bailey LR, Dupont WD, Parl FF \& Moore JH 2001 Multifactor-dimensionality reduction reveals high-order interactions among estrogenmetabolism genes in sporadic breast cancer. American Journal of Human Genetics 69 138-147.
Sandhu MS, Dunger DB \& Giovannucci EL 2002 Insulin, insulin-like growth factor-I (IGF-I), IGF binding proteins, their biologic interactions, and colorectal cancer. Journal of National Cancer Institute 94 972-980.

Schoen RE, Tangen CM, Kuller LH, Burke GL, Cushman M, Tracy RP, Dobs A \& Savage PJ 1999 Increased blood glucose and insulin, body size, and incident colorectal cancer. Journal of National Cancer Institute 91 1147-1154.

Slattery ML, Samowitz W, Curtin K, Ma KN, Hoffman M, Caan B \& Neuhausen S 2004 Associations among IRS1, IRS2, IGFI, and IGFBP3 genetic polymorphisms and colorectal cancer. Cancer Epidemiology, Biomarkers and Prevention 13 1206-1214.

Stephens RH, McElduff P, Heald AH, New JP, Worthington J, Ollier WE \& Gibson JM 2005 Polymorphisms in IGF-binding protein 1 are associated with impaired renal function in type 2 diabetes. Diabetes 54 3547-3553.

Wagner K, Hemminki K, Grzybowska E, Klaes R, Butkiewicz D, Pamula J, Pekala W, Zientek H, Mielzynska D, Siwinska E et al. 2004 The insulin-like growth factor-I pathway mediator genes: SHC1 Met300Val shows a protective effect in breast cancer. Carcinogenesis 25 2473-2478.

Wagner K, Hemminki K \& Forsti A 2007 The GH1/IGF-1 axis polymorphisms and their impact on breast cancer development. Breast Cancer Research Treatment 104 233-248.

Yoshizato K, Shirotani T, Furukawa N, Taguchi T, Motoshima H, Toyonaga T, Hirashima Y, Kawashima J, Ebina Y, Shichiri M et al. 2001 Identification of a cisacting element and a novel trans-acting factor of the human insulin receptor gene in HepG2 and rat liver cells. Biochemical and Biophysical Research Communications 280 428-434. 